Article

\title{
On the Substitutability between Paid-employment and Self-employment: Evidence from the Period 1969-2014 in the United States
}

\author{
Emilio Congregado ${ }^{1, *}$, Antonio A. Golpe ${ }^{1(\mathbb{C}}$ and Vicente Esteve ${ }^{2}(\mathbb{D}$ \\ 1 Department of Economics, University of Huelva, 21002 Huelva, Spain; antonio.golpe@dehie.uhu.es \\ 2 Department of Applied Economics II, University of Valencia, 46022 Valencia, Spain; vicente.esteve@uv.es \\ * Correspondence: congregado@uhu.es; Tel.: +34-959-217-832
}

Received: 29 November 2018; Accepted: 13 January 2019; Published: 18 January 2019

check for updates

\begin{abstract}
This paper provides estimates of the elasticity of substitution between operational and managerial jobs in the US economy during the years 1969-2014, derived from an aggregate CES production function. Estimating the long-term relationship between (the log of) the aggregate employment/self-employment ratio and (the log of) the returns from paid-employment relative to self-employment and testing for structural breaks, we report different estimates of the elasticity of substitution in each of the two regimes identified. To this end we apply the methodology on instability tests proposed in Kejriwal and Perron $(2008,2010)$ as well as the cointegration tests developed in Arai and Kurozumi (2007) and Kejriwal (2008). Our results help to understand and interpret one of the most intriguing aspects in the evolution of self-employment rates in developed countries: the reversal of the trend in self-employment rates. Our estimates show that a higher level of development is associated with a greater number of entrepreneurs and smaller firms. Some rationales for understanding the growth of the elasticity between paid-employment and self-employment, including the recent trends in the digital economy, are also suggested.
\end{abstract}

Keywords: elasticity of substitution; cointegration; business ownership; independent entrepreneurship; self-employment; structural breaks

\section{Introduction}

In recent years, a growing body of literature has studied the relation between economic development and the aggregate self-employment rate [1-6]. In particular, analysis of the interplay between the economic development phase and the evolution of the independent entrepreneurship rate-or the (inverse) relationship between the wealth of the economy and the related concept of average firm size (i.e., the employment/self-employment ratio) - has become a focus area for scholars because of the observation of a reversal in self-employment rate trends in several developed countries. A handful of works [7-9] documented this reversal trend in the US.

Until the last quarter of the 20th century, economic development was related to the everincreasing importance of economies of scale and scope [10], a switch from agriculture to manufacturing [11] and the influence of increasing wage levels on occupational choice [12].

Changes in industrial structure should influence independent entrepreneurship rates because some activities lend themselves better to self-employment than others [13]. One could argue that the characteristics of different sectors and industries, in terms of the existence of significant demand for personal (professional) services, jobs with erratic demand, the mix of skills required, or low capital requirements, make it more likely that a sector is populated by self-employed workers. These arguments help us to understand the high concentration of self-employed workers in the agriculture and service 
sectors and the comparatively low concentration in manufacturing. See, e.g., [14] for an analysis of US self-employment by industry.

In addition, some scholars highlight the relationship between stages of economic development, institutions, and entrepreneurship. For instance, changes in labour market institutions or the effects of the digital economy on the emergence of new forms of non-traditional employment can make easier for an individual to become an entrepreneur. From this perspective one would expect that those recent structural changes to be positively related with the higher probability of becoming an entrepreneur. If it were true the aggregate elasticity of substitution should reflect these changes caused by structural changes.

This paper investigates this latter hypothesis using US data, testing whether the estimate of the elasticity of substitution between managerial and operational jobs in a developed economy such as that of the US is compatible with a fall in average firm size. The aim of this paper is to present estimates of the elasticity of substitution between entrepreneurship and paid-employment using US data as a method of testing whether, as recent literature has hypothesised, wealthier and more developed countries are characterised by a higher elasticity of substitution between self-employment and paid-employment or if elasticity estimates instead support Lucas's hypothesis (in terms of the inexorability of a secular trend of increasing average firm size and decreasing numbers of entrepreneurs).

Our empirical results are consistent with the existence of a long-term relationship between the wage-earner/self-employment ratio and the relative earnings of self-employed and paid-employed workers. However, this relationship is subject to structural changes. In particular, our results report an elasticity estimate for the first subsample (before the break) that is consistent with Lucas's proposition regarding average firm size, while estimates in the second subsample are consistent with the observed evolution of average firm size. Importantly, the first break date coincides with the beginning of the rise in American self-employment [7]. Our estimates suggest that at the beginning of the 1990s, deep changes in the determinants of the substitution rate between self-employed and paid-employed workers, i.e., between managerial and operative works, should have occurred in such a manner that, in the most recent regime, self-employment and paid employment are now gross substitutes instead of complements. These findings are consistent with observed average firm size development in the US during the covered period.

Technically, our analysis parallels the literature on wage inequality [15] because we consider self-employment and paid employment as two employment statuses-managerial and operational works-similar to the literature addressing skilled and unskilled labour. Therefore, we report estimates of the elasticity of substitution between these two employment statuses by estimating the linear long-term relationship between the employment/self-employment ratio and the returns from paid-employment relative to self-employment. After analysis of this relationship, we consider the possibility that a regression model with multiple structural changes would provide a better empirical description of the relationship. To that end, instability tests, recently proposed in [16-18], are performed.

The remainder of the paper is organised as follows. In Section 2, we review previous literature. Section 3 describes the model, data and the econometric strategy. In Section 4, we present our estimation results. Section 5 reviews and put in perspective our findings. Finally, Section 6 summarises our main conclusions and present some avenues for further research.

\section{Literature Review}

The emergence of non-traditional forms of employment linked to the digital economy has re-opened the debate about whether the recent resurgence of self-employment should be interpreted in terms of entrepreneurship, i.e., due to structural changes or as a response to labour market rigidities. If that were the case, these new trends conflict with the traditional view on how entrepreneurs and salaried workers interact. 
Following Lucas's argument, because capital and labour are substitutes, higher capital stock implies higher returns from working and lower returns from managing. As a result, economic development leads to a higher average firm size because of a negative relationship between the elasticity of factor substitution (between capital and labour) and average firm size.

Overall, the predominant view was that as economies became wealthier, average firm size should increase; in other words, average firm size should be an increasing function of the wealth of the economy [19]. Therefore, a negative relation between economic development and the self-employment rate was implied. This negative relationship is well documented in the works of [11], [20-22], among others. Data regarding the evolution of average firm size during the late nineteenth and first three quarters of the twentieth centuries in most developed countries supported this proposition.

Related to this latter point, in a highly influential paper, [12] developed a model in which firm distribution was the solution to the problem of allocating productive factors among managers of varying ability. The main result of Lucas's model concerns the effect on average firm size when per capita capital increases. Lucas showed that in the case where the elasticity of substitution between labour and capital is less than one, as the economy becomes wealthier, the wage relative to managerial rents increases, and marginal entrepreneurs prefer to become wage earners rather than manage their own businesses. This causes an increase in the ability threshold that is necessary to become an entrepreneur, which defines the marginal entrepreneur. Then, an increase in wages, relative to a managerial rent increase, induces marginal entrepreneurs to become employees, raising the average size of the firm. By contrast, if the elasticity of substitution is greater than one, then economic increases in per capita capital increase the equilibrium number of entrepreneurs and decrease the average firm size. Note that in the case of a Cobb-Douglas production function, the average firm size is unchanged when per capita capital grows. Empirical estimates usually converge to an elasticity value-capital-labour-of less than 1 (see [23], ch. 3).

Furthermore, an important prediction, given the sustained trend of growth in capital per capita, emerges: "the fraction of entrepreneurs will decline over time while average firm size will inexorably increase" [13]. Development leads to higher average firm size because of a negative relationship between the elasticity of factor substitution and firm size.

Lucas [12] reported that average firm size (using employees per firm as a proxy) was positively related to GNP per capita (used as a proxy for capital per capita) in the US. This positive test of Lucas's hypothesis reflected not only observed developments in self-employment during the first three quarters of the 20th century but also consistency with estimations of the elasticity of factor substitution between capital and labour.

However, in several developed countries, the trend reversed. The relationship seemed to have changed from a negative relation to a positive one, and the observed recovery in self-employment rates was interpreted as undermining Lucas's prediction. In fact, the secular decline in self-employment rates experienced by most developed countries was followed by a reversal trend in the last quarter of the twentieth century and in the first decade of the current century. For instance, considering the $23 \mathrm{OECD}$ countries included in COMPENDIA (COMPENDIA is an acronym for COMParative ENtrepreneurship Data for International Analysis. See http: / / www.entrepreneurship-sme.eu.) as a reference, the average business ownership rate (Business ownership, self-employment and independent entrepreneurship will be used as interchangeable concepts in this article.) -i.e., the number of owners of non-agricultural incorporated and unincorporated businesses as a fraction of total labour force-increased from 0.100 in 1972 to 0.112 in 2009. This figure, however, hides huge national disparities in both levels of the average business ownership rate and in their evolution. For example, the sampled business ownership rates in 2009 range from $19.9 \%$ in Italy to $4.7 \%$ in Luxembourg; analysing the rates' evolution, business ownership in Japan experienced a decline from 0.125 in 1972 to 0.083 in 2009, while business ownership in the US and the European Union-15 increased from 0.082 to 0.093 and from 0.104 to 0.118 , respectively, during the same period [7,24-27]. The possibility of a U-shaped relationship between entrepreneurship 
and economic development gradually gained ground, and the re-examination of that relationship became the subject of a large body of empirical and theoretical literature, recently surveyed in [28].

Broadly speaking, at least four arguments have been suggested to explain this reversal [28]. The first argument relates to the non-validity of Lucas's proposition, asking whether something in the proposition itself is amiss or if the proposition depends crucially on some faulty assumption. Using this last argument, [29] extended Lucas's analysis by utilising a more general aggregate production function (a normalised CES), which allowed them to prove the existence of an inverse relationship between the elasticity of substitution (between capital and labour) and average firm size. From this perspective, the fact that wealthier countries have a higher elasticity of substitution is consistent with the positive association between the growing importance of SMEs in the most developed countries because a high elasticity of substitution value more easily enables individuals to become entrepreneurs. In short, from the model presented in [29], we can confidently state that in economies characterised by higher values of aggregate elasticity of substitution between capital and labour, we should expect higher wealth to be associated with more entrepreneurs and smaller firms. This proposition is supported by the recent evolution of average firm size in developed countries.

In addition to the above arguments, some scholars have suggested that there were also certain changes and mechanisms that can help to understand this trend reversal. One argument is that independent entrepreneurship and average firm size are now decreasing and increasing functions, respectively, of the wealth of the economy due to improvements in information and communication technologies (ICT). It is a well-known fact that the ICT revolution has decreased the importance of scale economies in many industries [30] and has increased opportunities for entrepreneurship and returns to entrepreneurship, managerial talent [31], and managerial works [32].

It has also been suggested that the reversal of the trend in self-employment rates may be the effect of an expansion of the business service sector relative to manufacturing. Several scholars argue that this expansion has attended a shift away from larger corporations and toward entrepreneurial activity. This phenomenon has led to a decline in the average firm size [28].

Finally, one could argue that the reversal in the business ownership rate may be the result of structural changes having strong effects on occupational choice decisions and, therefore, on the elasticity of substitution between paid-employment and self-employment. In particular, we may hypothesise that the above factors, in conjunction with the emergence of incentives schemes, such as subsidies or tax allowances [33-37], and a progressive reduction in the rights and benefits derived from employment protection legislation may have introduced substantial changes in the risk-adjusted relative earnings of paid employment and self-employment [38-45]. Thus, one could argue that higher levels of entrepreneurship may indicate that extant job creators are not creating attractive wage-earning job opportunities as a result of a low valuation of the risk associated with self-employment. The loss of rights, in terms of potential severance payments and unemployment benefits, may affect the structure of employment by altering the relative valuation between self-employment and paid-employment. In short, the importance of several factors-such as the reduction of the extent of scale economies, the existence of more volatile markets or the growing importance of innovation, and the elasticity of substitution between capital and labour-to predicting the progressive decline of the average firm size cannot be denied. This article seeks to test whether changes introduced in some labour market institutions [38] and labour market dynamics, along with the generalised emergence of entrepreneurship policy [46], particularly the introduction of different schemes to promote self-employment, have substantially altered the relative risk-adjusted returns in self-employment and the elasticity of substitution between them. 


\section{Material and Methods}

\subsection{The Econometric Model}

Generalising differences in individual skills in the basic occupational model (see, e.g., pioneer models of Rees and Shah [47], Borjas and Bronars [48], or Evans and Leighton [49], the choice between entrepreneurial-managerial and operational jobs is based upon the idea that individuals respond to the risk-adjusted relative earnings opportunities in each sector (self-employed sector vs. employed sector) $[50,51]$.

The perspective assumed in this paper is that occupational choices of fully informed individuals are based only on the risk-adjusted relative earnings between self-employment and paid-employment.

As mentioned, our empirical strategy parallels the basic framework used by literature addressing wage inequality and skill premiums-see e.g., the seminal works of Katz and Murphy [52], Autor et al. [53] and Acemoglu [15]_because, to some extent, the occupational decision between managerial and non-managerial work is also based on the relative earnings between the two employment statuses. Let us consider a simple closed economy. We begin with an aggregate production framework, where output is described by a constant elasticity of substitution production function of capital $K t$ and a labour aggregate $L t$ scaled by a technology parameter $A t$.

$$
Y_{t}=K_{t}^{\rho}\left(A L_{t}\right)^{1-\rho}
$$

The labour aggregate is a constant elasticity of substitution combination of wage earners, $E_{t}$, and self-employed workers, $S_{t}$, who carry out managerial activities, given by

$$
L_{t}=\left[\theta S_{t}^{1-\alpha}+(1-\theta) E_{t}^{1-\alpha}\right]^{\frac{1}{1-\alpha}}
$$

where $1 / \alpha$ represents the elasticity of substitution between wage earners and self-employed workers, and $\theta$ and $(1-\theta)$ are the distribution parameters that control the intensity with which self-employment and wage earners are used in production, respectively. The elasticity of substitution between the two factor inputs-operational and managerial work-measures the percentage response of the relative marginal products - returns - of the two factors to a percentage change in the ratio of their quantities. Therefore, salaried (operational) and self-employed (managerial) workers are gross substitutes (complements) when the elasticity of substitution is greater than (less than) one. In this framework, the value of the elasticity determines how changes in the relative supply of entrepreneurs and workers affect relative earnings of self-employed and paid-employed workers.

Let us define $W_{t}$ and $B_{t}$ as the aggregate incomes from paid-employment and self-employment, respectively. Given competitive markets, the relative returns should equate the relative marginal product of the two labour inputs,

$$
\frac{W_{t}}{B_{t}}=\frac{\partial Y / \partial E_{t}}{\partial Y / \partial S_{t}}=\frac{1-\theta}{\theta}\left(\frac{E_{t}}{S_{t}}\right)^{-\alpha}
$$

Assuming that the logarithm of the wage earners and self-employment series are I(1) processes, then a cointegrating regression implied by Equation (3) is given by

$$
\ln \left(\frac{W_{t}}{B_{t}}\right)=\mu-\alpha \ln \left(\frac{E_{t}}{S_{t}}\right)+\varepsilon_{t}
$$

where $\mu=\ln [(1-\theta) / \theta]$, the error term is an $\mathrm{I}(0)$ process with mean zero and $(1, \alpha)$ is the cointegrating vector.

This equation will serve as the basis for our empirical estimates. Our parameter of interest, $\alpha$, will be estimated by analysing the long-term relationship between (the log of) the employment/self-employment ratio and (the log of) the returns from paid-employment relative to self-employment. After confirming 
that these two variables are non-stationary, we will estimate the linear cointegration relation. However, because we are considering a long period of time, it is possible that the relationship between the two variables changes over time, i.e., it is possible that estimation of linear cointegration relations yields spurious inference results because of the presence of one or more structural breaks in the relation. Therefore, we consider the possibility that a linear cointegrated regression model with multiple structural changes would provide a better empirical description of the elasticity of substitution between self-employment and paid-employment. Our methodology is based on instability tests recently proposed in Kejriwal and Perron [16], as well as the cointegration test in Arai and Kurozumi [17] and Kejriwal [18], developed to allow for multiple breaks under a null hypothesis of cointegration.

\subsection{Data Collection and Analysis}

In our empirical analysis, we use US data for the period 1969-2014. As in most previous studies, entrepreneurship is operationalised in terms of self-employment, reflecting available data at the time-series level. We are conscious that entrepreneurship is a multifaceted concept, which encompasses a range of roles and activities, and that any single measure of entrepreneurship is therefore a limited proxy. However, in cross-country comparisons, by far the most common measure used in practice is self-employment rates, reflecting the widespread availability of data. Self-employment is not a perfect measure of entrepreneurship because it includes many "casual" businesses as well as long-established enterprises. Yet, as noted by entrepreneurship scholars, the self-employment definition has the merits of inclusiveness and convenience. Because the perspective adopted in this paper is closed to the Knightian entrepreneur [54] and because alternative (or additional) measures of entrepreneurship, such as those provided by the Global Entrepreneurship Monitor project, neither allow circumvention of these limitations nor provide sufficiently long time series for the analysis of long-term relationships, we recognise these difficulties and bear them in mind during the analysis below.

We use data on US self-employment $\left(S_{t}\right)$ and unemployment rates $\left(U_{t}\right)$,taken from the Bureau of Labor Statistics (Current Population Survey, CPS). The self-employment rate is defined as the share of non-farm employed people that is self-employed. For earnings, the source of the data is the Occupational Employment Statistics, by the United States Department of Labor. The longest available span of data available commences in 1969. The variable definitions and their main sources are given below:

$E_{t} / S_{t}$ : the paid-employment/self-employment ratio, use the wage and salary employment/ proprietorship ratio as a proxy.

$W_{t} / B_{t}$ : the relative earning of self-employed and paid-employed workers, i.e., the ratio between wage and salary disbursements and proprietor income.

We use yearly US data from the period 1969-2014, drawn from the Regional Economic Information System (REIS) of the Bureau of Economic Analysis. Table 1 reports summary statistics of the variables and ratios used in this study. Figure A1 in the Appendix A plots the time series.

Table 1. Descriptive Statistics.

\begin{tabular}{ccccccc}
\hline Heading & $\boldsymbol{W}_{\boldsymbol{t}}$ & $\boldsymbol{B}_{\boldsymbol{t}}$ & $\boldsymbol{E}_{\boldsymbol{t}}$ & $\boldsymbol{S}_{\boldsymbol{t}}$ & $\boldsymbol{W}_{\boldsymbol{t}} / \boldsymbol{B}_{\boldsymbol{t}}$ & $\boldsymbol{E}_{\boldsymbol{t}} / \boldsymbol{S}_{\boldsymbol{t}}$ \\
\hline Mean & 26,368 & 19,174 & $115,242,043$ & $21,763,128$ & 1.329 & 5.823 \\
Min & 6506 & 6645 & $78,722,000$ & $9,580,200$ & 0.971 & 3.676 \\
Max & 51,552 & 32,471 & $144,891,000$ & $39,066,800$ & 1.728 & 8.217 \\
Stdev & 14,025 & 8917 & $21,895,002$ & $9,058,028$ & 0.200 & 1.319 \\
\# obs. & 46 & 46 & 46 & 46 & 46 & 46 \\
\hline
\end{tabular}

Legend:

$W_{t}$ : Earnings from (non-farm) paid-employment, annual average, in \$

$B_{t}$ : Earnings from (non-farm) self-employment, annual average, in \$

$W_{t}$ : Non-farm paid-employment (\# of Jobs)

$S_{t}$ : Non-farm self-employment (\# of Jobs) 


\subsection{Econometric Methodology}

Accounting for parameter shifts is crucial in cointegration analysis since it normally involves long spans of data, which are more likely to be affected by structural breaks [55]. In the works of Bai and Perron [56] we can find a general framework for dealing with multiple structural changes in linear regression models. In particular, Kejriwal and Perron [16,57] provide an econometric methodology for testing structural changes in cointegrated systems. In short, they consider a linear model with $\mathrm{m}$ multiple structural changes and $m+1$ regimes.

$$
y_{t}=c_{j}+z_{f t}^{\prime} \delta_{f}+z_{b t}^{\prime} \delta_{b j}+x_{f t}^{\prime} \beta_{f}+x_{b t}^{\prime} \beta_{b j}+u_{t} \quad\left(t=T_{j-1}+1, \ldots, T_{j}\right)
$$

for $j=1, \ldots, m+1$, where $T_{0}=0, T_{m+1}=T$, and $T$ the sample size. In this model, $y_{t}$ is a scalar dependent I $(1)$ variable, $x_{f t}\left(p_{f} \times 1\right)$ and $x_{b t}\left(p_{b} \times 1\right)$ are vectors of I $(0)$ variables, while $z_{f t}\left(q_{f} \times 1\right)$ and $z_{b t}\left(q_{b} \times 1\right)$ are vectors of I $(1)$ variables. The break points $\left(T_{1}, \ldots, T_{m}\right)$ are treated as unknown.

The general model (5) is a partial structural change model in which the coefficients of only a subset of the regressors are subject to change. In our case, we suppose that $p_{f}=p_{b}=q_{f}=0$, and the estimated model is a pure structural change model with all coefficients of the I(1) regressors and constant allowed to change across regimes:

$$
y_{t}=c_{j}+z_{b t}^{\prime} \delta_{b j}+u_{t} \quad\left(t=T_{j-1}+1, \ldots, T_{j}\right)
$$

Generally, the assumption of strict exogeneity is too restrictive and the test statistics for testing multiple breaks are not robust to the problem of endogenous regressors. To deal with the possibility of endogenous I(1) regressors, Kejriwal and Perron [16,57] propose to use the so-called dynamic OLS regression (DOLS) where leads and lags of the first-differences of the I(1) variables are added as regressors, as suggested by Stock and Watson [58]:

$$
y_{t}=c_{j}+z_{b t}^{\prime} \delta_{b j}+\sum_{j=-l_{T}}^{l_{T}} \Delta z_{b t-j}^{\prime} \Pi_{b j}+u_{t}^{*} \quad \text { if } T_{j-1}<t \leq T_{i}
$$

for $j=1, \ldots, k+1$, where $k$ is the number of breaks, $T_{0}=0$, and $T_{k+1}=T$.

\subsubsection{Structural Break Tests}

We test the parameter instability in cointegration regression using the tests proposed in Kejriwal and Perron $[16,57]$. They present issues related to structural changes in cointegrated models which allows both $\mathrm{I}(1)$ and $\mathrm{I}(0)$ regressors as well as multiple breaks. They also propose a sequential procedure which permits consistent estimation of the number of breaks, as in Bai and Perron [56].

Kejriwal and Perron [16] consider three types of test statistics for testing multiple breaks. First, they propose a sup Wald test of the null hypothesis of no structural break $(m=0)$ versus the alternative hypothesis that there are a fixed (arbitrary) number of breaks $(m=k)$ :

$$
\operatorname{supF}_{T}^{*}(k)=\sup _{\lambda \in \Lambda \varepsilon} \frac{S S R_{0}-S S R_{k}}{\hat{\sigma}^{2}}
$$

where $S S R_{0}$ denotes the sum of squared residuals under the null hypothesis of no breaks, $S S R_{k}$ denotes the sum of squared residuals under the alternative hypothesis of $\mathrm{k}$ breaks, $\left\{\lambda_{1}, \ldots, \lambda_{m}\right\}$ as the vector of breaks fractions defined by $\lambda_{i}=T_{i} / T$ for $i=1, \ldots, m, T_{i}$, and $T_{i}$ are the break dates.

Secondly, they consider a test of the null hypothesis of no structural break ( $m=0)$ versus the alternative hypothesis that there is an unknown number of breaks given some upper bound $\mathrm{M}(1 \leq m \leq \mathrm{M})$ :

$$
U \operatorname{Dmax}_{T}^{*}(k)=\max _{1 \leq k \leq m} F_{T}^{*}(k)
$$


In addition to the tests above, Kejriwal and Perron [16] consider a sequential test of the null hypothesis of $k$ breaks versus the alternative hypothesis of $k+1$ breaks:

$$
S E Q(k+1 \mid k)=\max _{1 \leq j \leq k+1} \sup _{\tau \in \Lambda j, \varepsilon} T\left\{S S R_{T}\left(\hat{T}_{1}, \ldots, \hat{T}_{k}\right)\right\}-\left\{S S R_{T}\left(\hat{T}_{1}, \ldots, \hat{T}_{j-1}, \tau, \hat{T}_{j}, \ldots, \hat{T}_{k}\right)\right\} / S S R_{k+1}
$$

where $\Lambda_{j, \varepsilon}\left\{\tau: \hat{T}_{j-1}+\left(\hat{T}_{j}-\hat{T}_{j-1}\right) \varepsilon \leq \tau \leq \hat{T}_{j}-\left(\hat{T}_{j}-\hat{T}_{j-1}\right) \varepsilon\right\}$. The model with $k$ breaks is obtained by a global minimization of the sum of squared residuals, as in Bai and Perron (1998).

\subsubsection{Cointegration Tests with Structural Changes}

Kejriwal and Perron [16,57] show that the structural change tests can suffer from important lack of power against spurious regression (i.e., no cointegration). This means that these tests can reject the null of stability when the regression is really a spurious one. In this sense, tests for breaks in the long-run relationship are used in conjunction with tests for the presence or absence of cointegration allowing for structural changes in the coefficients.

First, we use the residual-based test of the null of cointegration with an unknown single break against the alternative of no cointegration proposed in Arai and Kurozumi [17]. They propose a LM test based on partial sums of residuals where the break point is obtained by minimizing the sum of squared residuals and consider three models: (i) Model 1, level shift; (ii) Model 2, level shift with trend; (iii) and Model 3, regime shift.

The LM test statistic (for one break), $\hat{V}_{k}(\hat{\lambda})$, is given by:

$$
\hat{V}_{k}(\hat{\lambda})=\left(T^{-2} \sum_{t=1}^{T} S_{t}(\hat{\lambda})^{2}\right) / \hat{\Omega}_{11}
$$

where $\hat{\Omega}_{11}$ is a consistent estimate of the long-run variance of $\mathrm{u}_{t}^{*}$ in (7), the date of break $\hat{\lambda}_{i}=\left(\hat{T}_{1} / T, \ldots, \hat{T}_{k} / T\right)$ and $\left(\hat{T}_{1}, \ldots, \hat{T}_{k}\right)$ are obtained using the dynamic algorithm proposed in Bai and Perron [56].

The Arai and Kurozumi [17] test is restrictive in the sense that only a single structural break is considered under the null hypothesis. Hence, the test may tend to reject the null of cointegration when the true data generating process exhibits cointegration with multiple breaks. To avoid this problem, Kejriwal [18] has recently extended their test by incorporating multiple breaks under the null hypothesis of cointegration. The Kejriwal [18] test of the null of cointegration with multiple structural changes is denoted with $k$ breaks as $\hat{V}_{k}(\hat{\lambda})$.

\section{Research Results}

In this section we revisit the issue of the substitutability between employees and independent entrepreneurs using instability tests to account for potential breaks in the long-run relationship between (the log of) the employment/self-employment ratio and (the log of) the returns from paid-employment relative to self-employment as well as the cointegration tests with multiple breaks. As we mentioned, first, we use unit root tests to verify that the two series are individually integrated of order one. Second, we test the stability of the relationship (and select the number of breaks) using the test proposed in Kejriwal and Perron [16]. Third, we verify that the variables are cointegrated with tests for the presence/absence of cointegration allowing for a single or multiple structural changes in the coefficients as proposed by Arai and Kurozumi [17] and Kejriwal [18], respectively. Finally, we estimate the model incorporating the breaks in order to study if the relationship (in particular the slope parameter) has changed over time.

\subsection{Testing for Unit Roots}

Because estimation of a linear cointegration model requires the series to be non-stationary, we start by testing for a unit root in the employment/self-employment ratio and the returns from 
paid-employment relative to self-employment. We apply the class of unit root tests developed by $\mathrm{Ng}$ and Perron [59] which solve several statistical problems associated with more "conventional" unit root tests. In general, the majority of the conventional unit root tests such as the Dickey-Fuller tests and the Phillips-Perron tests suffer from three problems. First, many tests have low power when the root of the autoregressive polynomial is close to but less than one [60]. Second, most tests suffer from severe size distortions when the moving-average polynomial of the first-differenced series has a large negative autoregressive root $[61,62]$. Third, the implementation of unit root tests often requires the selection of an autoregressive truncation lag $\mathrm{k}$; however, as discussed in $\mathrm{Ng}$ and Perron [63], there is a strong association between $\mathrm{k}$ and the severity of size distortions and/or the extent of power loss. $\mathrm{Ng}$ and Perron [59] solved these problems, and we refer to their article for further details. All test statistics formally examine the unit root null hypothesis against the stationary alternative. Table 2 reports the results. As shown, the existence of two unit roots is clearly rejected at the usual significance levels for all variables, and the null hypothesis of non-stationarity in levels is clearly rejected at the usual significance levels for both variables. Thus, according to the results of these tests, these two series would be I(1).

Table 2. Ng and Perron tests for a unit root.

\begin{tabular}{|c|c|c|c|c|c|c|c|}
\hline \multirow{2}{*}{$\begin{array}{l}\text { I(2) vs. I(1) } \\
\text { Variable }\end{array}$} & \multicolumn{7}{|c|}{ Case: $\mathbf{p}=0, \bar{c}=7.0$} \\
\hline & $\bar{M} Z_{\alpha}^{G L S}$ & \multicolumn{2}{|c|}{$\bar{M} Z_{t}^{G L S}$} & \multicolumn{2}{|c|}{$\bar{M} S B_{\alpha}^{G L S}$} & \multicolumn{2}{|c|}{$\bar{M} P_{T}^{G L S}$} \\
\hline$E_{t} / S_{t}$ & $-16.161^{* * *}$ & \multicolumn{2}{|c|}{$-2.796^{* * *}$} & \multicolumn{2}{|c|}{$0.173^{* * *}$} & \multicolumn{2}{|c|}{$1.691^{* * *}$} \\
\hline$W_{t} / B_{t}$ & $-13.519 * *$ & \multicolumn{2}{|c|}{$-2.568^{* *}$} & \multicolumn{2}{|c|}{$0.190^{* *}$} & \multicolumn{2}{|c|}{$1.936^{* *}$} \\
\hline \multicolumn{2}{|l|}{ I(1) vs. I(0) } & \multicolumn{4}{|c|}{ Case: $p=1, \bar{c}=-13.5$} & & \\
\hline$E_{t} / S_{t}$ & -4.469 & & & & & \multirow{2}{*}{\multicolumn{2}{|c|}{$\begin{array}{l}20.084 \\
17.843\end{array}$}} \\
\hline$W_{t} / B_{t}$ & -5.106 & & & & & & \\
\hline \multicolumn{2}{|c|}{ Critical Values: } & \multicolumn{3}{|c|}{ Case: $\mathrm{p}=0, \bar{c}=-7.0$} & \multicolumn{3}{|c|}{ Case: $p=1, \bar{c}=-13.5$} \\
\hline \multicolumn{2}{|c|}{ Variable } & $10 \%$ & $5 \%$ & $1 \%$ & $10 \%$ & $5 \%$ & $1 \%$ \\
\hline \multicolumn{2}{|c|}{$\bar{M} Z_{\alpha}^{G L S}$} & -5.7 & -8.1 & -13.8 & -14.2 & -17.3 & -23.8 \\
\hline \multicolumn{2}{|c|}{$\bar{M} S B_{\alpha}^{G L S}$} & 0.275 & 0.233 & 0.174 & 0.185 & 0.168 & 0.143 \\
\hline \multicolumn{2}{|c|}{$\bar{M} Z_{t}^{G L S}$} & -1.62 & -1.98 & -2.58 & -2.62 & -2.91 & -3.42 \\
\hline \multicolumn{2}{|c|}{$\bar{M} P_{T}^{G L S}$} & 4.45 & 3.17 & 1.78 & 6.67 & 5.48 & 4.03 \\
\hline
\end{tabular}

Notes: ${ }^{* *}$ and ${ }^{* * *}$ denote significance at the $5 \%$ and $1 \%$ levels, respectively; The MAIC information criteria are used to select the autoregressive truncation lag, $k$, as proposed in Perron and $\mathrm{Ng}$ (1996). The critical values are taken from Ng and Perron (2001), table 1. Obs. 46.

\subsection{Looking for Structural Breaks}

Having confirmed the non-stationarity of both variables, we now apply the tests for structural change that have been proposed by Kejriwal and Perron [16,57]. We use a 15\% trimming, which limits the maximum number of breaks allowed under the alternative hypothesis to 1 . Both the intercept and the slope are allowed to change.

Table 3 shows the results of the stability tests and the number of breaks selected by the sequential procedure proposed by Bai and Perron [56] as well as the Bayesian and the modified Schwarz information criteria (BIC and LWZ, respectively). The supFT (1) test is significant at the $5 \%$ level, unlike supFT (2), suggesting that the data do not support a one-break model, although the BIC and LWZ select one break and provide evidence against the stability of the long-term relationship. Overall, the results of the Kejriwal-Perron tests suggest a model with one break, estimated at 1992, and two regimes: 1969-1992 and 1993-2014.

Because the above stability tests reject the null coefficient stability when the regression is spurious, we need to confirm the presence of cointegration among the variables. We use the residual-based test of the null of cointegration against the alternative of cointegration with unknown multiple breaks proposed in Kejriwal [18], $\hat{V}(\hat{\lambda})$. Arai and Kurozumi [17] show that the limit distribution of the test 
statistic, $\hat{V}_{k}(\hat{\lambda})$, depends only upon the timing of the estimated break fraction $\hat{\lambda}$ and the number of I(1) regressors $\mathrm{m}$. In our case (one-break model), critical values are obtained for $\hat{\lambda}=0.585$, and $\mathrm{m}=1$ by simulation using 500 steps and 2000 replications. The Wiener processes are approximated by partial sums of i.i.d. $\mathrm{N}(0,1)$ random variables. Table 4 shows the results of the Arai-Kurozumi cointegration test, allowing one break. Again, the level of trimming used is $15 \%$. The results show that the test $\hat{V}_{1}(\hat{\lambda})$ cannot reject the null of cointegration with one structural breaks at 1992 . Once the presence of structural breaks has been confirmed, and to compare the coefficients obtained from a one-break model with those reported from a model without any structural break, we proceed with a comparison of the estimates of the elasticity of substitution obtained from a one-break model with those obtained from the full sample.

Table 3. Kerjiwal-Perron tests for testing multiple structural breaks.

\begin{tabular}{ccccc}
\hline & & \multicolumn{3}{c}{ Number of Breaks Selected } \\
\hline SupF $_{t}(1)$ & $U D_{\max }$ & Sequential & BIC & $L W Z$ \\
\hline \multirow{2}{*}{5.393} & \multirow{2}{*}{5.393} & 0 & 1 & 1 \\
\cline { 3 - 5 } & & $T_{b}$ & $T_{b}$ & $T_{b}$ \\
\hline Obs. 46 & & & 1992 & 1992 \\
\hline
\end{tabular}

Table 4. Arai-Kurozumi-Kejriwal cointegration tests with one structural break.

\begin{tabular}{ccccc}
\hline Test $\hat{V}(\hat{\lambda})$ & $\hat{\lambda}$ & $\hat{T}_{1}$ & & \\
\hline 0.062 & 0.585 & 1992 & & \\
Critical values & $10 \%$ & $5 \%$ & $1 \%$ \\
\multicolumn{2}{c}{$\hat{V}_{k}(\hat{\lambda})$} & 0.108 & 0.135 & 0.218 \\
\hline
\end{tabular}

Note: Critical values are obtained by simulation using 500 steps and 2000 replications. The Wiener processes are approximated by partial sums of i.i.d. $\mathrm{N}(0,1)$ random variables. Obs. 46.

\subsection{Elasticity Estimates}

For the full sample, we estimate the long-term regression model using the Dynamic Ordinary Least Squares (DOLS) estimation method of Stock and Watson [58], extended by Shin [64]. The Shin approach is similar to the KPSS tests [65], which, in the case of cointegration, are implemented in two stages.

Therefore, the first step in our estimation strategy consists of the estimation of a long-term dynamic equation, including leads and lags of the explanatory variables in the long-term regression model, i.e., the so-called DOLS regression:

$$
\ln \left(\frac{W_{t}}{B_{t}}\right)=\delta-\alpha \ln \left(\frac{E_{t}}{S_{t}}\right)+\sum_{j=-q}^{q} \varphi_{j} \Delta \ln \frac{E_{t-j}}{S_{t-j}}+\varepsilon_{j}
$$

In the second step, we use the statistic $C \mu$, a LM-type test designed by Shin [64], to test the null of cointegration against the alternative of no cointegration in DOLS regression. In Table 5, we report the estimates from the DOLS regression and the results from Shin's test. The results show that the null of deterministic cointegration is not rejected at the $1 \%$ significance level.

Because there is strong evidence of the presence of structural breaks in 1992 for the cointegration relationship, we divide our sample into two subsamples to analyse whether the elasticity of substitution changes before and after the breaks. We estimate equation (5) for the two subsamples. The estimates for the subsamples are reported in the last two columns of Table 5. In the two regimes, we cannot reject the null of deterministic cointegration at the $1 \%$ level of significance. We obtain significant estimates of $\alpha$, i.e., estimated values for $\hat{\alpha}=1.089$ and 0.786 . These parameter estimates imply that the values 
of the elasticity of substitution are 0.918 and 1.272 for the first, and second subsamples, respectively. Thus, ignoring shifts may cause rejection of the existence of a long-term cointegration relationship between the employment/self-employment ratio and the relative earnings of self-employed and paid-employed workers.

Table 5. Stock-Watson-Shin's Dynamic Ordinary Least Squares (DOLS) estimation of linear cointegration.

\begin{tabular}{cccc}
\hline Parameter Estimates & $\begin{array}{c}\text { Full Sample } \\
\text { 1969-2014 }\end{array}$ & $\begin{array}{c}\text { First Regime } \\
\mathbf{1 9 6 9 - 1 9 9 2}\end{array}$ & $\begin{array}{c}\text { Second Regime } \\
\mathbf{1 9 9 3 - 2 0 1 4}\end{array}$ \\
\hline$\delta$ & $0.923^{* *}$ & $2.185^{* * *}$ & $1.610^{* * *}$ \\
$\alpha$ & $(0.385)$ & $(0.243)$ & $(0.241)$ \\
$1 / \alpha$ & $0.359^{* * *}$ & $1.089^{* * *}$ & $0.786^{* * * *}$ \\
$(0.190)$ & $(0.116)$ & $(0.141)$ \\
\hline Test: $C_{\mu}^{c}$ & 2.785 & 0.918 & 1.272 \\
$R^{2}$ & 0.117 & 0.137 & 0.131 \\
$\hat{\sigma}^{2}$ & 0.617 & 0.960 & 0.924 \\
\hline Critical values & 0.093 & 0.034 & 0.049 \\
\hline$C_{\mu}$ & $\mathbf{1 0 \%}$ & $\mathbf{5 \%}$ & $\mathbf{1 \%}$ \\
\hline
\end{tabular}

Notes: Standard Errors (in brackets) are adjusted for long-term variance. The long-term variance of the cointegrating regression residual is estimated using the Barlett window, which is approximately equal to $\operatorname{INT}\left(T^{1 / 2}\right)$, as proposed in Newey and West (1987). We choose $q=I N T\left(T^{1 / 3}\right)$, as proposed in Stock and Watson (1993). $C_{\mu}$ is a LM statistic for cointegration using the DOLS residuals from deterministic cointegration, as proposed by Shin (1994). ${ }^{* *}$ and ${ }^{* * *}$ denote significance at the $5 \%$ and $1 \%$ levels, respectively. Obs. 46 .

Furthermore, the evolution of the US average firm size (self-employment rate) is consistent with the elasticity estimates for the two identified regimes. In particular, our results report an elasticity estimate for the first subsample (before the first break), which is consistent with Lucas's proposition regarding average firm size. In contrast, after this first regime, the elasticity experienced drastic growth, and the elasticity reached a value higher than one. Therefore, the estimates suggest that at the beginning of the 1990s, deep changes in the determinants of the substitution rate between self-employed and paid-employed workers, i.e., between managerial and operative works, should have taken place in such a manner that, in the most recent regime, self-employment and paid employment are now gross substitutes instead of complements. These findings are consistent with the evolution of observed average firm size in the US during the covered period.

\section{Discussion}

The results support the existence of a changing and increasing elasticity of substitution between paid employment and self-employment, supporting both the proposition of et al. [29] regarding the decrease in average firm size and the observed evolution of the US self-employment rate.

This change in the elasticity of substitution conforms to the observed relation between average firm size and economic development in advanced economies. However, the relation has been subject to change. Until the last quarter of the twentieth century, the increasing importance in economies of scale and the influence of increasing wage levels on occupational choice implied a growing average firm size (Chandler [10], Wennekers et al., [28]). However, starting in the 1980s, self-employment levels started to increase in many advanced economies, beginning in the US. There are some factors that could explain this structural change in the elasticity of substitution, i.e., some driving forces of this shift toward smallness: (i) the fast-growing services sector, with its minor scale and lower entry barriers; (ii) an opposite relationship between the elasticity of substitution between labour and capital and average firm size (Aquilina et al.'s proposition); (iii) a trend in occupational preferences favouring self-employment following the emergence of incentive schemes; (iv) globalisation conforming with the spread of ICT (information and communication technologies), allowing solo entrepreneurs and small firms to reap the 
fruits of scale economies through loosely organised networks; and finally, (v) new technologies' creation of opportunities for new technology-based business start-ups (Wennekers et al., [28], p. 169).

Recently, Amorós and Cristi [66] presented another argument for economies in which some individuals are 'pushed' into entrepreneurship because no better employment options exist, despite the existence of pro-entrepreneurship policies. Most likely, this argument can also be applied to developed countries where the change in the relative response of the employment/self-employment ratio to changes in the relative earnings of self-employed and paid-employed workers has led to a lower average self-employed firm size, as shown by our empirical estimates. This paper reported estimates of the elasticity of substitution with the incorporation of breaks to study how the relationship may have changed over time as well as to estimate the elasticity in every regime in a developed economy.

It is likely that necessity entrepreneurship (Acs et al, [67]), new interactions between labour market institutions and the promotion of self-employment and/or a new risk-adjusted valuation of the relative returns between managerial and operational works in a context of less-protected paid-employment are factors that might explain the elasticity estimates reported in this study. Further research is needed to determine whether changes in institutional conditions may explain the documented changes in the elasticity of substitution provided in this article.

\section{Conclusions}

This paper reported estimates of the elasticity of substitution in the US, accounting for the possible existence of structural breaks. Using a methodology based on instability tests recently proposed in Kejriwal and Perron [16] as well as the cointegration tests in Arai and Kurozumi [17] and Kejriwal [18] that were developed to allow for multiple breaks under the null hypothesis of cointegration, our results support the existence of a changing and increasing elasticity of substitution between paid employment and self-employment, supporting the decrease in average firm size observed in most developed economies.

Our findings are consistent with some previous empirical research as well as one of the theoretical frameworks proposed by previous researchers. Our findings also add to the debate in the scholarly literature, where they may even help reconcile some disparate prior empirical findings.

One important avenue for future research is to obtain time series data for different measures and conceptualizations of entrepreneurship. Alternative measures of entrepreneurship might exhibit different relationships with paid employment, consistent with alternative hypotheses about how occupational decisions can change in response to socio-economic and structural changes. In that sense, we are aware that self-employment is not an unambiguously valid operationalization of entrepreneurship, and we recognize the likely sensitivity of empirical results to the use of different entrepreneurship measures as a limitation of this study. However, we were unable to find an alternative (or supplementary) measure to self-employment for a sufficiently long period to conduct time series analysis. This limitation should be borne in mind when interpreting the scope of our results. In sum, we have not stated a formal hypothesis but our findings nevertheless provide a basis for cutting through the muddled picture painted by the various theories. This line of reasoning also leaves the door open for different empirical regularities if entrepreneurship is operationalized differently in future research.

Several questions still remain, however. While the current research has made a first approach in demonstrating the power of suitable econometric techniques to uncover the instability in the relationship between paid-employment and self-employment, a need in this area would be to conduct more exhaustive research that furthers understanding of the precise mechanisms at play.

To conclude, we believe the present article advances our understanding of the interaction between self-employment and paid-employment and points to the emergence of radical changes like the instability of the elasticity of substitution shows.

Author Contributions: Conceptualization, E.C., A.A.G; Methodology, V.E., A.A.G; Software, V.E., A.A.G; Validation, V.E., A.A.G; Formal analysis, E.C.; Investigation, E.C., V.E., A.A.G; Data, A.A.G; Writing-Original 
Draft Preparation, E.C., V.E., A.A.G; Writing-Review and Editing, E.C., V.E. A.A.G.; Visualization, V.E., A.A.G; Supervision, E.C., V.E., A.A.G.

Funding: This research received no specific grant from any funding agency in the public, commercial or not-for-profit sectors.

Acknowledgments: The authors would like to thank the three anonymous reviewers for their insightful and constructive feedback. Emilio Congregado and Antonio A. Golpe are members of the Spanish Entrepreneurship Research Group (SERG) SEJ-487 funded by the Andalusian Government and acknowledge the financial support from the Spanish Ministry of Economy and Competitiveness (Project ref. ECO2017-86402-C2-2-R). Vicente Esteve acknowledges the financial support from the Spanish Ministry of Economy, Industry and Competitiveness through the project ECO2017-83255-C3-3-P and the Generalitat Valenciana (Project GVPROMETEO 2018/102).

Conflicts of Interest: The authors declare no conflict of interest.

\section{Appendix A}

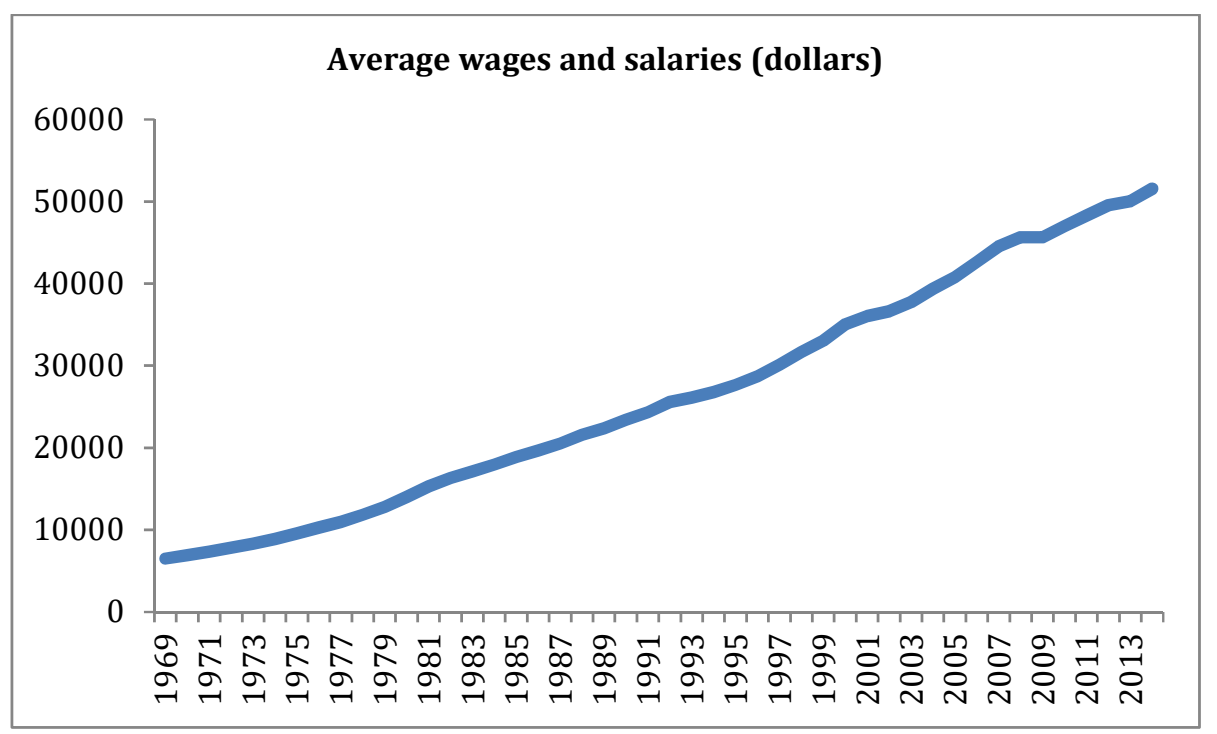

(a)

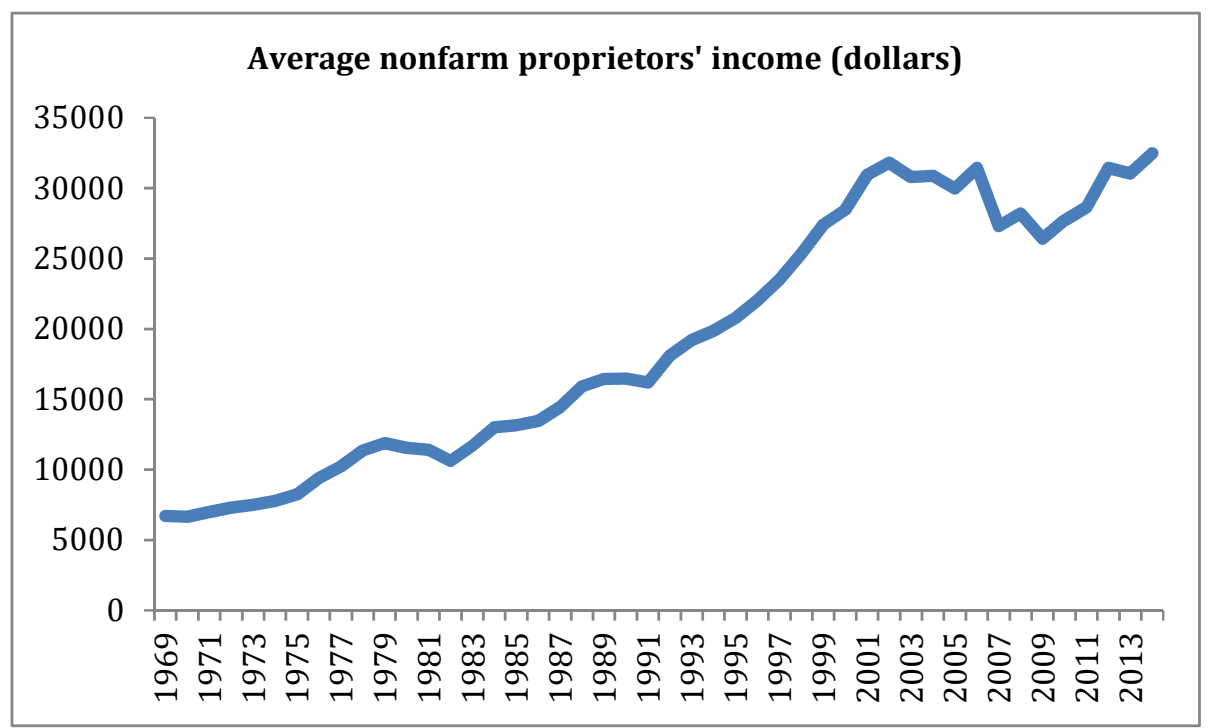

(b)

Figure A1. Cont. 


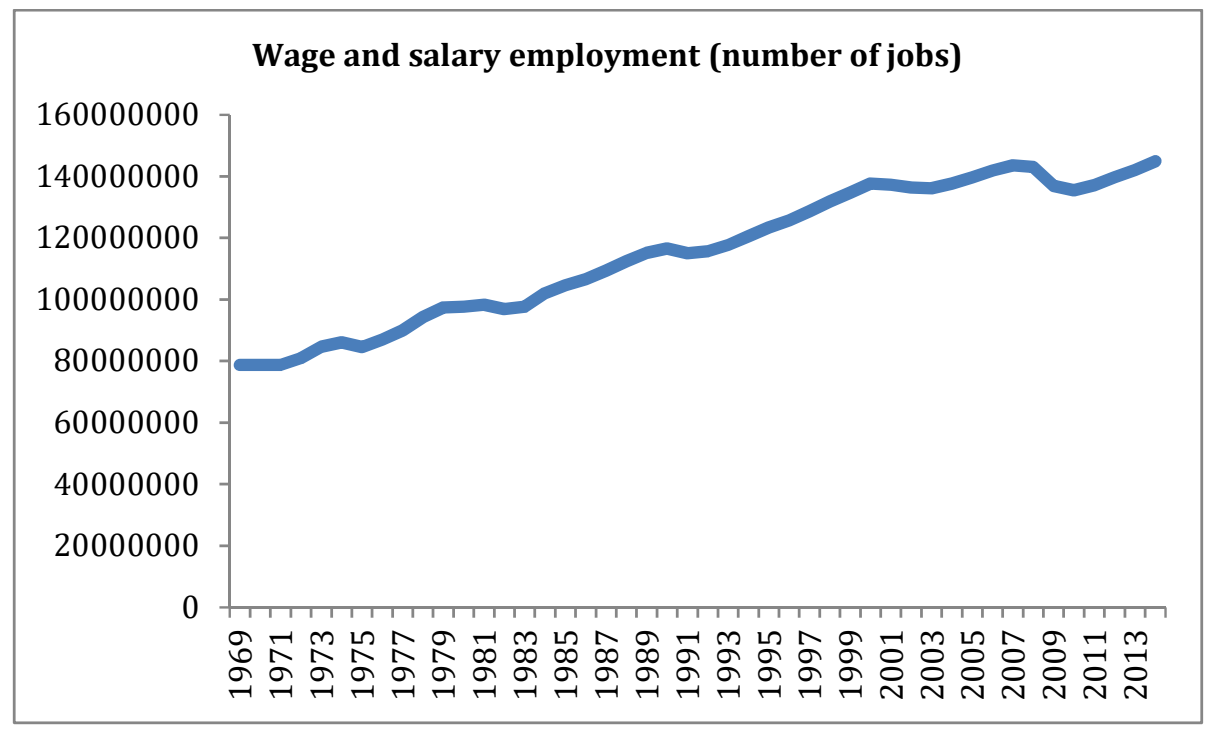

(c)

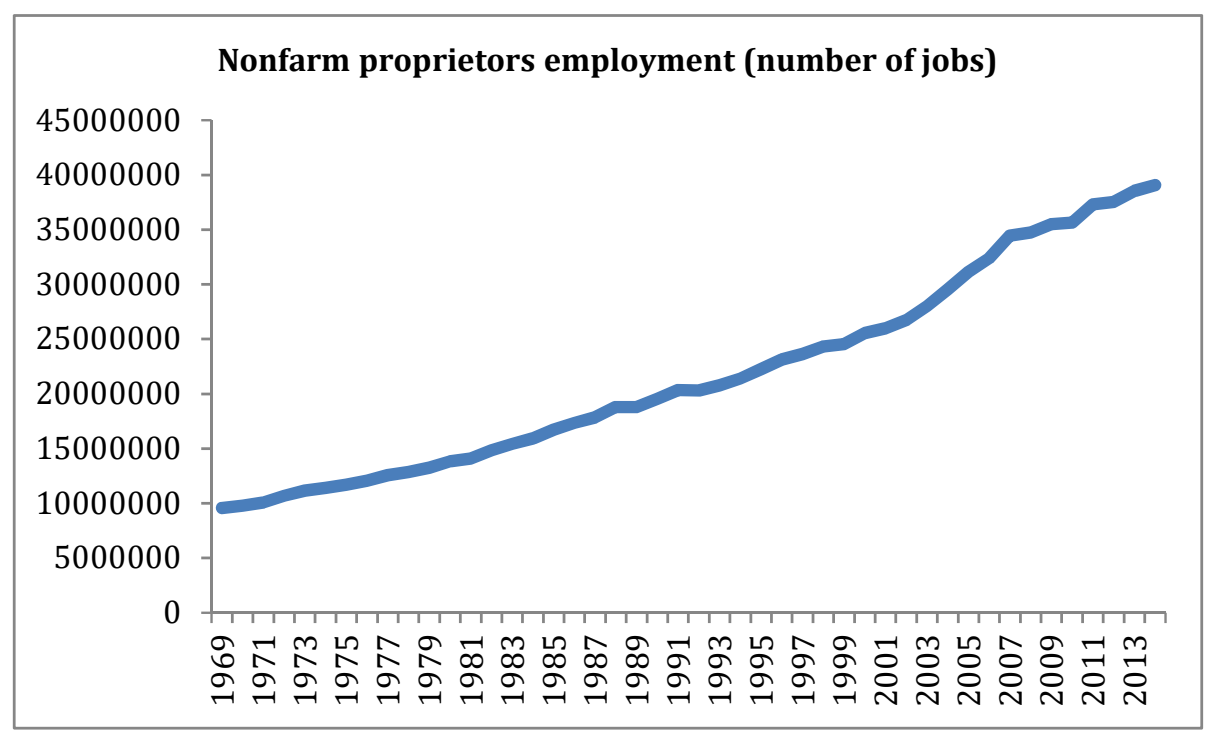

(d)

Figure A1. Plots of time series. Note: (a): Wages; (b): Income; (c): Wage employment; (d): Propietors employment.

\section{References}

1. Carree, M.; Van Stel, A.; Thurik, R.; Wennekers, S. Economic Development and Business Ownership: An Analysis Using Data of 23 OECD Countries in the Period 1976-1996. Small Bus. Econ. 2002, 19, 271-290. [CrossRef]

2. Carree, M.; Van Stel, A.; Thurik, R.; Wennekers, S. The Relationship Between Economic Development and Business Ownership Revisited. Entrep. Reg. Dev. 2007, 19, 281-291. [CrossRef]

3. Dvouletý, O.; Lukeš, M. Review of Empirical Studies on Self-Employment out of Unemployment: Do Self-Employment Policies Make a Positive Impact? Int. Rev. Entrep. 2016, 14, 361-376.

4. Audretsch, D.B.; Belitski, M.; Desai, S. Entrepreneurship and economic development in cities. Ann. Reg. Sci. 2015, 55, 33-60. [CrossRef]

5. Acs, Z.J.; Estrin, S.; Mickiewicz, T.; Szerb, L. Entrepreneurship, institutional economics, and economic growth: An ecosystem perspective. Small Bus. Econ. 2018, 51, 501-514. [CrossRef] 
6. Dhahri, S.; Omri, A. Entrepreneurship contribution to the three pillars of sustainable development: What does the evidence really say? World Dev. 2018, 106, 64-77. [CrossRef]

7. Fain, T.S. Self-employed Americans: Their number has increased. Mon. Lab. Rev. 1980, 103, 3-8.

8. Blau, D. A time series analysis of self-employment. J. Polit. Econ. 1987, 95, 445-467. [CrossRef]

9. Acs, Z.J.; Audretsch, D.B.; Evans, D.S. The Determinants of Variation in the Self-Employment Rates Across Countries and Over Time; Discussion Paper DP871; Centre for Economic Policy Research: London, UK, 1994.

10. Chandler, A.D. Scale and Scope: The Dynamics of Industrial Capitalism; Harvard University Press: Cambridge, MA, USA, 1990.

11. Kuznets, S. Economic Growth of Nations, Total Output and Production Structure; Harvard University Press/Belknapp Press: Cambridge, MA, USA, 1971.

12. Lucas, R.E. On the size distribution of business firms. Bell J. Econ. 1978, 9, 508-523. [CrossRef]

13. Parker, S.C. The Economics of Self-Employment and Entrepreneurship; Cambridge University Press: Cambridge, MA, USA, 2004.

14. Aronson, R.L. Self-Employment: A Labour Market Perspective; ILR Press: Ithaca, NY, USA, 1991.

15. Acemoglu, D. Technical Change, Inequality, and the Labor Market. J. Econ. Lit. 2002, 40, 7-72. [CrossRef]

16. Kejriwal, M.; Perron, P. Testing for multiple structural changes in cointegrated regression models. J. Bus. Econ. Stat. 2010, 28, 503-522. [CrossRef]

17. Arai, Y.; Kurozoumi, E. Testing for the null hypothesis of cointegration with a structural break. Econom. Rev. 2007, 26, 705-739. [CrossRef]

18. Kejriwal, M. Cointegration with structural breaks: An application to the Feldstein-Horioka Puzzle. Stud. Nonlinear Dynam. Econom. 2008, 12,1-37. [CrossRef]

19. Acs, Z.J. How Is Entrepreneurship Good for Economic Growth? Innovations 2006, 1, 97-107. [CrossRef]

20. Schultz, T.P. Women's changing participation in the labor force: A world perspective. Econ. Dev. Cult. Chang. 1990, 38, 457-488. [CrossRef]

21. Yamada, G. Urban informal employment and self-employment in developing countries: Theory and evidence. Econ. Dev. Cult. Chang. 1996, 44, 289-314. [CrossRef]

22. Iyigun, M.F.; Owen, A.L. Risk, Entrepreneurship and Human-Capital Accumulation. Am. Econ. Rev. 1998, 88, 454-457. [CrossRef]

23. Hamermesh, D.S. Labour Demand; Princeton University Press: Princeton, NJ, USA, 1996.

24. Bregger, J.E. Measuring Self-employment in the United States. Mon. Lab. Rev. 1996, 119, 3-9.

25. Hipple, S.F. Self-employment in the United States: An update. Mon. Lab. Rev. 2004, 127, $24-47$.

26. Hipple, S.F. Self-employment in the United States. Mon. Lab. Rev. 2010, 133, 17-32.

27. Karoly, L.A.; Zissmopoulos, J. Self-Employment Trends and Patterns Among Older U.S. Workers. Mon. Lab. Rev. 2004, 9, 24-47.

28. Wennekers, S.; van Stel, A.; Carree, M.; Thurik, A.R. The relationship between entrepreneurship and economic development: Is it U-shaped. Found. Trends Entrep. 2010, 6, 167-237. [CrossRef]

29. Aquilina, M.; Klump, R.; Pietrobelli, C. Factor Substitution, Average Firm Size and Economic Growth. Small Bus. Econ. 2006, 26, 203-214. [CrossRef]

30. Carlsson, B. The evolution of manufacturing technology and its impact on industrial structure: An international study. Small Bus. Econ. 1989, 1, 21-38. [CrossRef]

31. Thompson, N.; Eijkemans, R. Why Do Sustainable Ventures Fail to Attract Management Talent? Sustainability 2018, 10, 4319. [CrossRef]

32. Parker, S.C.; Robson, M.T. Explaining international variations in self-employment: Evidence from a panel of OECD countries. Southern Econ. J. 2004, 7, 287-301. [CrossRef]

33. Robson, M.T.; Wren, C. Marginal average tax rates and the incentive for self-employment. Southern Econ. J. 1999, 65, 757-773. [CrossRef]

34. Schuetze, H.J. Taxes, economic conditions and recent trends in male self-employment: A Canada-US comparison. Lab. Econ. 2000, 7, 507-544. [CrossRef]

35. Parker, S.C. Does tax evasion affect occupational choice? Oxf. Bull. Econ. Stat. 2003, 65, 379-394. [CrossRef]

36. Bruce, D.; Schuetze, H.J. Tax Policy and Entrepreneurship. Swed. Econ. Pol. Rev. 2004, 2, 233-265.

37. Schuetze, H.J. Tax Incentives and Entrepreneurship: Measurement and Data Considerations. In Measuring Entrepreneurship; Congregado, E., Ed.; Springer: New York, NY, USA, 2008; pp. 205-225. 
38. Botero, J.; Djankov, S.; La Porta, R.; Lopez-de-Silanes, R.; Shleifer, A. The Regulation of Labor. Q. J. Econ. 2004, 119, 1339-1382. [CrossRef]

39. Grubb, D.; Wells, W. Employment regulation and patterns of work in EC countries. OECD Econ. Stud. 1993, 21, 7-58.

40. Robson, M.T. Does stricter employment protection legislation promote self-employment? Small Bus. Econ. 2003, 21, 309-319. [CrossRef]

41. Kanniainen, V.; Vesala, T. Entrepreneurship and labour market institutions. Econ. Model. 2005, $22,828-847$. [CrossRef]

42. Torrini, R. Cross-country differences in self-employment rates: The role of institutions. Lab. Econ. 2005, 12, 661-683. [CrossRef]

43. Van Stel, A.; Storey, D.; Thurik, A.R. The Effect of Business Regulations on Nascent and Young Business Entrepreneurship. Small Bus. Econ. 2007, 28, 171-186. [CrossRef]

44. Nyström, K. The institutions of economic freedom and entrepreneurship: Evidence from panel data. Public Choice 2008, 136, 269-282. [CrossRef]

45. Roman, C.; Congregado, E.; Millán, J.M. Dependent self-employment as a way to evade employment protection legislation. Small Bus. Econ. 2011, 37, 363-392. [CrossRef]

46. Hart, D.M. The Emergence of Entrepreneurship Policy; Cambridge University Press: Cambridge, UK, 2003.

47. Rees, H.; Shah, A. An empirical analysis of self-employment in the U.K. J. Appl. Econom. 1986, 1, 95-108. [CrossRef]

48. Borjas, G.J.; Bronars, S.G. Consumer Discrimination and Self-employment. J. Polit. Econ. 1989, 97, 581-605. [CrossRef]

49. Evans, D.; Leighton, L.S. Some Empirical Aspects of Entrepreneurship. Am. Econ. Rev. 1989, 79, 519-535.

50. Kihlstrom, R.; Laffont, J. A General Equilibrium Entrepreneurial Theory of the Firm. J. Polit. Econ. 1979, 87, 719-748. [CrossRef]

51. Banerjee, A.V.; Newman, A.F. Occupational Choice and the Process of Development. J. Polit. Econ. 1993, 101, 274-298. [CrossRef]

52. Katz, L.; Murphy, K. Changes in Relative Wages: Supply and Demand Factors. Q. J. Econ. 1992, 107, 35-78. [CrossRef]

53. Autor, D.; Katz, L.; Krueger, A. Computing Inequality: Have Computers Changed the Labor Market? Q. J. Econ. 1998, 113, 1169-1214. [CrossRef]

54. Iversen, J.; Jorgensen, R.; Malchow-Moller, N. Defining and Measuring Entrepreneurship. Found. Trends Entrep. 2008, 4, 1-63. [CrossRef]

55. Esteve, V.; Tamarit, C. Public debt and economic growth in Spain, 1851-2013. Cliometrica 2018, 12, $219-249$. [CrossRef]

56. Bai, J.; Perron, P. Critical Values for Multiple Structural Change Tests. Econ. J. 2003, 6, 72-78. [CrossRef]

57. Kejriwal, M.; Perron, P. The limit distribution of the estimates in cointegrated regression models with multiple structural changes. J. Econ. 2008, 146, 59-73. [CrossRef]

58. Stock, J.H.; Watson, M.W. A simple estimator of cointegrating vectors in higher order integrated systems. Econometrica 1993, 61, 783-820. [CrossRef]

59. Ng, S.; Perron, P. Lag length selection and the construction of unit root tests with good size and power. Econometrica 2001, 69, 1529-1554. [CrossRef]

60. DeJong, D.N.J.; Nankervis, J.C.; Savin, N.E.; Whiteman, C.H. Integration versus trend stationary in time series. Econometrica 1992, 60, 423-433. [CrossRef]

61. Schwert, G.W. Tests for unit roots: A Monte Carlo investigation. J. Bus. Econ. Stat. 1989, 7, 147-159.

62. Perron, P.; $\mathrm{Ng}, \mathrm{S}$. Useful modifications to some unit root tests with dependent errors and their local asymptotic properties. Rev. Econ. Stud. 1996, 63, 435-465. [CrossRef]

63. Ng, S.; Perron, P. Unit Root Tests in ARMA Models with Data Dependent Methods for the Selection of the Truncation Lag. J. Am. Stat. Assoc. 1995, 90, 268-281. [CrossRef]

64. Shin, Y. A residual-based test of the null of cointegration against the alternative of no cointegration. Econ. Theory 1994, 10, 91-115. [CrossRef]

65. Kwiatkowski, D.; Phillips, P.C.B.; Schmidt, P.; Shin, Y. Testing the null hypothesis of stationarity against the alternative of a unit root: How sure are we that economic time series have a unit root? J. Econ. 1992, 54, 159-178. [CrossRef] 
66. Amorós, J.E.; Cristi, O. Longitudinal analysis of entrepreneurship and competitiveness dynamics in Latin America. Int. Entrep. Manag. J. 2008, 4, 381-399. [CrossRef]

67. Acs, Z.J.; Desai, S.; Hessels, J. Entrepreneurship, economic development and institutions. Small Bus. Econ. 2008, 31, 219-234. [CrossRef] 